\title{
Stability of micro dry wire EDM: OFAT and DOE method
}

\section{Asfana Banu ${ }^{1} \cdot{\text { Mohammad Yeakub } \text { Ali }^{2} \cdot \text { Mohamed Abdul Rahman }}^{1} \cdot$ Mohamed Konneh $^{3}$}

Received: 19 September 2019 / Accepted: 2 January 2020 / Published online: 14 January 2020

(C) Springer-Verlag London Ltd., part of Springer Nature 2020

\begin{abstract}
Micro dry wire electrical discharge machining $(\mu D W E D M)$ is an environmental-friendly machining process where gas is used as the dielectric fluid instead of liquid. In this process, certain modifications of wire electrical discharge machining (WEDM) are required during the machining operation for stable machining. In $\mu$ DWEDM, the process is considered stable if the machining is continuous without any interruption due to wire breakage or wire lag. However, in the present state of the arts, stable and smooth machining process using $\mu$ DWEDM remains a critical issue. Hence, the objectives of this research are to establish a stable $\mu$ DWEDM process using two different experimental approaches: one-factor-at-a-time (OFAT) and design of experiment (DOE) method. The investigation was performed on a stainless steel (SS304) with a tungsten wire as the electrode using integrated multiprocess machine tool, DT 110 (Mikrotools Inc., Singapore). Types of dielectric fluid, dielectric fluid pressure, polarity, threshold voltage, wire tension, wire feed rate, wire speed, gap voltage, and capacitance were the controlled parameters. The machining length of the microchannels was measured using scanning electron microscope (SEM) (JEOL JSM-5600, Japan). Analysis based on these two experimental approaches shows that stable $\mu$ DWEDM process is achievable when the types of dielectric fluid, dielectric fluid pressure, polarity, threshold voltage, wire tension, wire feed rate, and wire speed remain as the fixed parameters while the capacitance and gap voltage remain as the controlled parameters.
\end{abstract}

Keywords Dry EDM $\cdot$ DEDM $\cdot$ DWEDM $\cdot \mu$ DWEDM $\cdot$ OFAT $\cdot$ DOE $\cdot$ Plackett-Burman design

\section{Introduction}

Electrical discharge machining (EDM) process has the ability to fabricate high-precision products for communication, aerospace, and automotive industries [1-6]. It is a thermal machining process where the machined area of the workpiece is removed by the thermal energy created by the electrical spark $[4,7,8]$. The electrical sparking process is a repetitive and

Mohammad Yeakub Ali

yeakub.ali@utb.edu.bn

1 Department of Manufacturing and Materials Engineering, Faculty of Engineering, International Islamic University Malaysia, P.O. Box 10, 50728 Kuala Lumpur, Malaysia

2 Mechanical Engineering Programme Area, Faculty of Engineering, Universiti Teknologi Brunei, Tungku Highway, Gadong, Bandar Seri Begawan BE1410, Brunei Darussalam

3 Department of Mechanical and Maintenance Engineering, Faculty of Engineering, Fourah Bay College, University of Sierra Leone, Freetown, Sierra Leone discrete process which is carried out in dielectric fluid [4, 7-9].

Dielectric fluid plays a significant role during the machining process where it helps to improve the efficiency of the machining process, improve quality of the machined parts, and flush away the debris from the machining gap. Usually, the dielectric fluids are in the form of mineral oil-based liquid or hydrocarbon oils. However, these types of dielectric fluids have certain deficiencies that are related to fire hazard and environmental problems [9-12]. Therefore, the alternative to overcome this problem is to use gas dielectric instead of liquid dielectric during the machining process $[3,4,9-11]$.

The idea of using gas instead of liquid as the dielectric fluid is not fully agreed by certain researchers because of the erosion effect. Normally, the erosion effect is small when the sparks are generated in the air due to the energy lost. Moreover, one of the key functions of the dielectric fluid is to restrict the spark generation where higher density of energy is achievable during the machining process. This mechanism is only applicable when the dielectric fluid is in the liquid form [13-15]. Normally, the dynamic plasma pressure rises and the bubble of vapour expands when the sparks are in the liquid 
dielectric. However, due to the restriction of the plasma growth caused by the surrounding of the liquid dielectric, the bubble collapses and removes the molten metal out of the crater when the temperature decreases [13, 14]. As a result, higher amount of materials is removed when the liquid dielectric is used during the machining process compared to the gas dielectric [15]. Despite the disagreements, gas as the dielectric fluid for EDM process was first introduced by NASA in 1985 which is known as the dry EDM (DEDM) $[9,14]$.

Conventional experimental method, one-factor-at-a-time (OFAT), and statistical experimental method, design of experiment (DOE) [16, 17], are two types of experimental approach used in conducting this research. OFAT is a conventional experimental method where only one factor varies at a time while the other factors are kept constant $[16,17]$. According to some researchers, OFAT proves to be inefficient and unreliable because it can lead to false optimal conditions. The precision of the estimation of the factor is low since this method is usually regarded as trial and error. This is because the experimental conclusions are drawn after data collection for each trial run and are compared with the observed outcome from the previous result [17]. Even though this method is not suggested by the statistical community, it is widely used in the industrial application. This is because the statistical design only covers the experimental region within the constraints imposed by the number of test runs allowed [18].

On the other hand, DOE is a statistical experimental method in determining the relationship between factors affecting a process and the output of that process [17]. Plackett-Burman design is a type of DOE $[19,20]$ where it allows two levels for each of the control factors, $k$, just like a $2^{k}$ design, yet with much smaller number of experimental runs, $n$ especially when $k$ is large. The total number of experiments, $n$, normally is equal to $k+1 ; k=$ number of factors. Moreover, the design is desirable only when $n$ is a multiple of 4 which means the number of control factor $k$ is equal to $3,7,11$, and $15[20,21]$. However, for factors that are not assigned, they are known as dummies. These dummies factors are used to estimate the error in order to get high-quality information on the significance of each "real" factor [21-23]. It is useful in various screening experiments due to its flexibility in

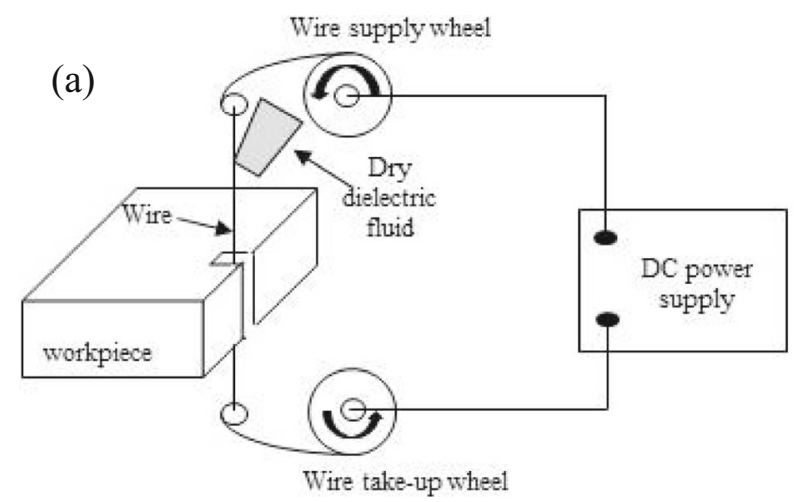

accommodating various combinations of factors with different numbers of levels. However, it is capable only in estimating the main effects of the factors rather than their interactions since it has a complex aliasing structure [19]. Thus, the objective of this research is to establish stable micro dry wire EDM ( $\mu$ DWEDM) process using two different experimental approaches which are the OFAT and DOE methods.

\section{Methodology}

Micro dry wire EDM ( $\mu$ DWEDM) process was performed using an integrated multi-process machine tool DT-110 (Mikrotools Inc., Singapore). Stainless steel (SS304) plate $(30 \mathrm{~mm} \times 20 \mathrm{~mm} \times$ $0.5 \mathrm{~mm}(\mathrm{t}))$ and tungsten $(\mathrm{W})$ wire $(\varnothing 70 \mu \mathrm{m})$ were used as the workpiece and the electrode respectively. Miniaturise products for electronic components such as the micro-fins are normally fabricated using stainless steel $[10,24,25]$. This material is preferable due to its high hardenability and resistance against corrosion [10]. On the other hand, tungsten wire with radius between 0.025 and $0.1 \mathrm{~mm}$ has high tensile strength, > $1900 \mathrm{MPa}$, and high loadcarrying capacity. It has the ability to machine small features with high tolerance and good surface $[10,26]$.

The workpiece was first grounded manually using 320 , 400,600 , and 800 grades of sandpapers respectively. Subsequently, the workpiece was cleaned in ethanol using ultrasonic cleaning machine (BRANSON 2510, Virginia) within $5 \mathrm{~min}$. The machining operation was conducted using $\mu$ DWEDM process after the sample preparation was completed as shown by the schematic diagram in Fig. 1a. After the machining, the workpiece once again was cleaned in ethanol for $5 \mathrm{~min}$ using ultrasonic cleaning machine. The measurements of the microchannels machining length were determined using scanning electron microscope (SEM) (JEOL JSM-5600, Japan) as shown in Fig. 1b. SEM is a type of electron microscope, where high-resolution three-dimensional images are produced [10].

In $\mu$ DWEDM, the process is considered stable and smooth if the machining is continuous without any interruption due to

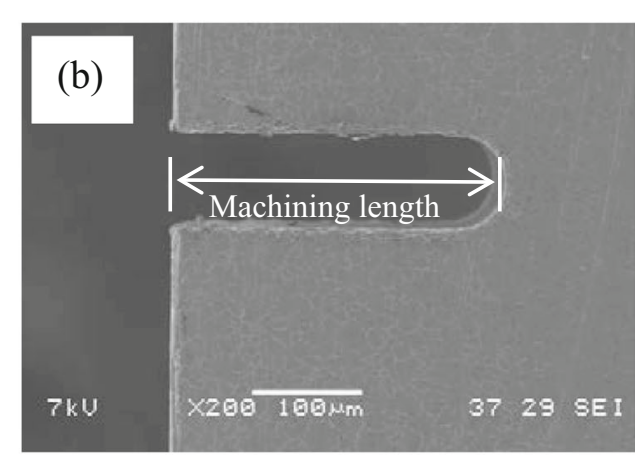

Fig. 1 a Schematic diagram of the $\mu$ DWEDM process and $\mathbf{b}$ measurement of the machining length estimated using SEM 
any reasons such as wire breakage and wire lag. Therefore, for this investigation, the machining was continued until the wire breaks and or machining stops by itself even though the wire did not break. The machining process has the tendency to stop when the wire electrode touches and or stuck at the machined surface. Thus, the machining time was not recorded while the machining length was used as the response to determine the stability of the $\mu$ DWEDM process. Due to this circumstance, the selections of the parameters were based on the literature review, capability of machine, type of machining materials, and tool electrode $[10,25]$. There were two types of experimental approach used for this investigation, OFAT and Plackett-Burman design, which are discussed in the following subsections.

\subsection{OFAT}

At the beginning of this study, the parameters and their levels were totally unknown since $\mu D W E D M$ is a new process in the field of micromachining. Besides that, previous literature also did not reveal anything regarding this matter based on the literature review done. Therefore, random selection of parameters was chosen to find the parameters that can at least machine the workpiece. In this way, the parameters and their levels were identified one by one. The parameters involved during this investigation were types of dielectric fluid, dielectric fluid pressure, polarity, threshold voltage, wire tension, wire feed rate, wire speed, gap voltage, and capacitance. The experimentation approach used for this phase was OFAT. This approach was chosen due to the simplicity in explaining the fundamentals of the machining mechanism. For each of the selected factors, the experiments were repeated three times. It means that three different microchannels were machined for each of the experiments. The average of the machining length from these three microchannels and their standard deviations were calculated. The results are presented by the graphs in Section 3. The controlled and fixed parameters are listed in Table 1.

\subsection{Plackett-Burman design}

Plackett-Burman design is normally used for screening purposes since it has the ability in estimating the main effects of the factors or parameters [19,27]. This design was executed to verify statistically the results of the OFAT method. Therefore, the selection of the parameters and their levels used are similar to the OFAT approach. The controlled and fixed parameters together with their levels are tabulated in Table 2. Table 2 also shows the values of the parameters for the high and low levels which are identical to the highest and lowest values used during the OFAT method (Table 1). For this investigation, the Plackett-Burman design that fits for nine controlled parameters were twelve numbers of experiments. This is because the design is worthwhile only when the total number of experiments, $n$, is a multiple of 4 where the number of control parameters, $k$, is equal to 3,7 , and $11[20,21]$. Since there were only nine parameters, two dummies were added so that the total number of controlled parameters would equal to eleven; $k=9+2=11$. As a result, a total of twelve experiments $(n=$ 12) were generated as shown in Table 3. The dummies' factors are the factors that are not assigned; it helps in estimating the error to get quality info on the significance of the main factors [21-23]. Each of the experiments was replicated three times and the average of the machining length is tabulated in Table 3. The data were analysed using analysis of variance (ANOVA) approach at 5\% significance level [27] discussed in Section 4.
Table $1 \mu$ DWEDM conditions for OFAT method

\begin{tabular}{ll}
\hline & Experimental conditions \\
\hline Controlled parameters & \\
Dielectric fluid & Atmospheric air, compressed air \\
Dielectric fluid pressure for compressed air $(\mathrm{MPa})$ & $0.0345,0.0689,0.1034$ \\
Polarity & Workpiece positive, Workpiece negative \\
Threshold voltage $(\%)$ & $25,24,23$ \\
Wire tension $(\mathrm{N})$ & $0.0809,0.1214$ \\
Wire feed rate $(\mu \mathrm{m} / \mathrm{s})$ & $0.2,0.4$ \\
Wire speed $(\mathrm{rpm})$ & $0.5,0.6$ \\
Capacitance $(\mathrm{nF})$ & $100,10,1.00,0.10,0.01$ \\
Gap voltage $(\mathrm{V})$ & $80,90,100,110$ \\
Fixed parameters & \\
Workpiece & Stainless steel $(\mathrm{SS} 304)(30 \mathrm{~mm} \times 20 \mathrm{~mm} \times 0.5 \mathrm{~mm}(\mathrm{t}))$ \\
Electrode & Tungsten wire $(\varnothing 70 \mu \mathrm{m})$ \\
Machining length $(\mu \mathrm{m})$ & 300 \\
\hline
\end{tabular}


Table $2 \mu$ DWEDM conditions for Plackett-Burman design

\begin{tabular}{llcc}
\hline Controlled parameters & Symbols & Coded levels & \\
\cline { 3 - 4 } & & Low $(-1)$ & High $(+1)$ \\
\hline Dielectric fluid & $A$ & Atmospheric air & Compressed air \\
Dielectric fluid pressure $(\mathrm{MPa})$ & $B$ & 0.0345 & 0.1034 \\
Workpiece polarity & $C$ & Negative & Positive \\
Threshold voltage $(\%)$ & $D$ & 23 & 25 \\
Wire tension $(\mathrm{N})$ & $E$ & 0.0809 & 0.1214 \\
Wire feed rate $(\mu \mathrm{m} / \mathrm{s})$ & $F$ & 0.2 & 0.4 \\
Wire speed $(\mathrm{rpm})$ & $G$ & 0.5 & 0.6 \\
Capacitance $(\mathrm{nF})$ & $H$ & 0.01 & 100 \\
Gap voltage $(\mathrm{V})$ & $J$ & 80 & 110 \\
Dummy1 & $K$ & -1 & +1 \\
Dummy2 & $L$ & -1 & \\
Fixed parameters & & & \\
$\quad$ Workpiece & Stainless steel $(\mathrm{SS} 304)(30 \mathrm{~mm} \times 20 \mathrm{~mm} \times 0.5 \mathrm{~mm}(\mathrm{t}))$ & \\
Electrode & Tungsten wire $(\varnothing 70 \mu \mathrm{m})$ & & \\
Machining length $(\mu \mathrm{m})$ & 300 & &
\end{tabular}

\section{Results and analysis for OFAT}

\subsection{Dielectric fluid}

Dielectric fluid is important in initiating the electrical discharges between the two electrodes: wire electrode and workpiece. In addition, it also helps in improving the efficiency of the machining process as well as flushes away the debris from the machining gap [9-12]. Figure 2 shows the graph of machining length with respect to gap voltage for combination of dielectric fluid and dielectric fluid pressure. Based on the graph, it was found that only minor machining was possible, machining lengths $<75 \mu \mathrm{m}$, when atmospheric air was used as the dry dielectric fluid during the machining process. The $\mu$ DWEDM process has the tendency to stop when the machining continues further than the machining length. It happens due to the wire breakage [10]. However, when compressed air with $0.0345 \mathrm{MPa}$ was used as the dry dielectric fluid during $\mu$ DWEDM process, the machining was stable and smooth, machining lengths $>150 \mu \mathrm{m}$. It is due to the breakdown voltage mechanism that occurs in gases. The breakdown voltage (micro-breakdown) phenomenon as stated by the modified Paschen's law is only dependent on the gap distance between the electrodes, $d$, rather than the gas pressure and the gap

Table 3 Plackett-Burman design for 12 runs of experiments

\begin{tabular}{|c|c|c|c|c|c|c|c|c|c|c|c|c|}
\hline Exp & $\begin{array}{l}A: \\
\text { dielectric } \\
\text { fluid }\end{array}$ & $\begin{array}{l}B: \text { dielectric } \\
\text { fluid pressure } \\
(\mathrm{MPa})\end{array}$ & $\begin{array}{l}C: \\
\text { workpiece } \\
\text { polarity }\end{array}$ & $\begin{array}{l}D: \\
\text { threshold } \\
\text { voltage } \\
(\%)\end{array}$ & $\begin{array}{l}E: \text { wire } \\
\text { tension } \\
(\mathrm{N})\end{array}$ & $\begin{array}{l}F: \text { wire } \\
\text { feed rate } \\
(\mu \mathrm{m} / \mathrm{s})\end{array}$ & $\begin{array}{l}G: \text { wire } \\
\text { speed } \\
(\mathrm{rpm})\end{array}$ & $\begin{array}{l}H: \\
\text { capacitance } \\
(\mathrm{nF})\end{array}$ & $\begin{array}{l}J: \text { gap } \\
\text { voltage } \\
(\mathrm{V})\end{array}$ & $\begin{array}{l}K: \\
\text { dummy } \\
1\end{array}$ & $\begin{array}{l}L: \\
\text { dummy } \\
2\end{array}$ & $\begin{array}{l}\text { Response: } \\
\text { average } \\
\text { machining } \\
\text { length }(\mu \mathrm{m})\end{array}$ \\
\hline 1 & 1 & -1 & 1 & -1 & -1 & -1 & 1 & 1 & 1 & -1 & 1 & 100.73 \\
\hline 2 & 1 & 1 & -1 & 1 & -1 & -1 & -1 & 1 & 1 & 1 & -1 & 3.33 \\
\hline 3 & -1 & 1 & 1 & -1 & 1 & -1 & -1 & -1 & 1 & 1 & 1 & 7.23 \\
\hline 4 & 1 & -1 & 1 & 1 & -1 & 1 & -1 & -1 & -1 & 1 & 1 & 93.60 \\
\hline 5 & 1 & 1 & -1 & 1 & 1 & -1 & 1 & -1 & -1 & -1 & 1 & 8.50 \\
\hline 6 & 1 & 1 & 1 & -1 & 1 & 1 & -1 & 1 & -1 & -1 & -1 & 96.63 \\
\hline 7 & -1 & 1 & 1 & 1 & -1 & 1 & 1 & -1 & 1 & -1 & -1 & 6.20 \\
\hline 8 & -1 & -1 & 1 & 1 & 1 & -1 & 1 & 1 & -1 & 1 & -1 & 45.47 \\
\hline 9 & -1 & -1 & -1 & 1 & 1 & 1 & -1 & 1 & 1 & -1 & 1 & 1.33 \\
\hline 10 & 1 & -1 & -1 & -1 & 1 & 1 & 1 & -1 & 1 & 1 & -1 & 1.67 \\
\hline 11 & -1 & 1 & -1 & -1 & -1 & 1 & 1 & 1 & -1 & 1 & 1 & 5.33 \\
\hline 12 & -1 & -1 & -1 & -1 & -1 & -1 & -1 & -1 & -1 & -1 & -1 & 2.67 \\
\hline
\end{tabular}


Fig. 2 Graph of machining length with respect to gap voltage for combination of dielectric fluid and dielectric fluid pressure as indicated by the legend. $(1 \mathrm{nF}$ capacitance, $24 \%$ threshold voltage, workpiece positive polarity, $0.2 \mu \mathrm{m} / \mathrm{s}$ wire feed rate, $0.0809 \mathrm{~N}$ wire tension, and $0.5 \mathrm{rpm}$ wire speed. The pressure for the compressed air was $0.0345 \mathrm{MPa})$

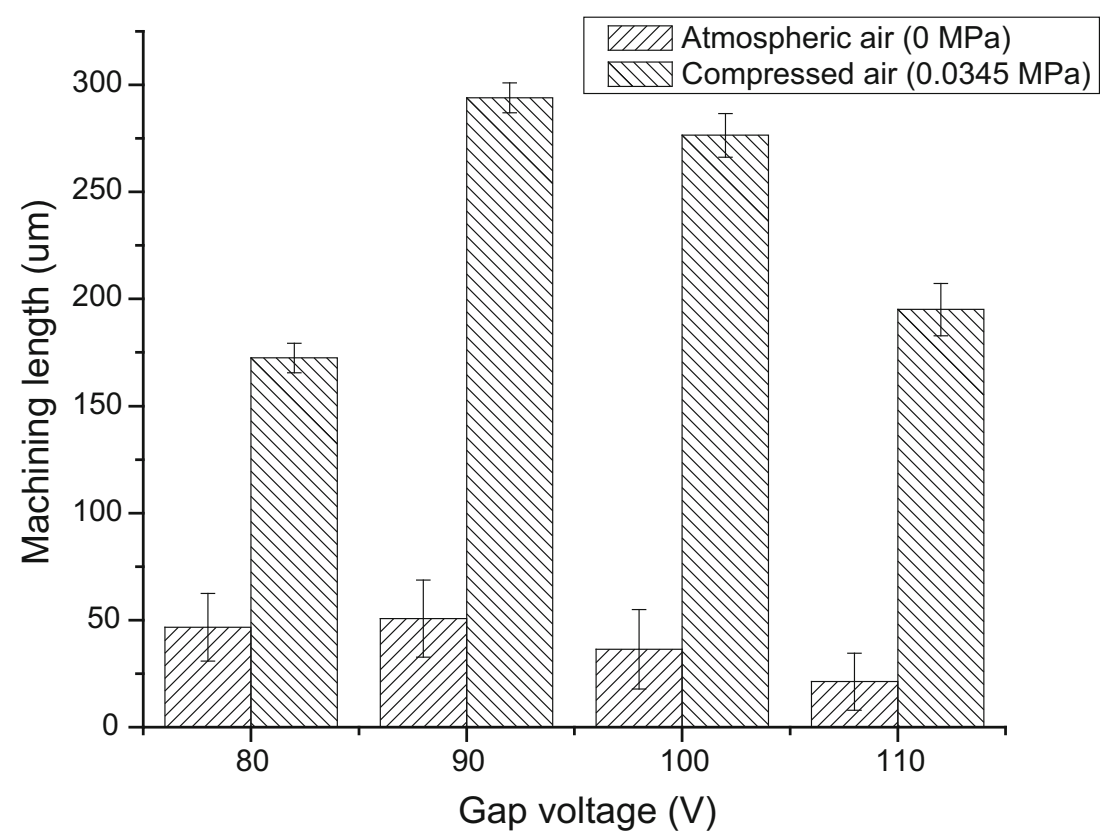

distance between the electrodes $(p d)$ as declared by the classical Paschen's law [10, 28-34]. However, in this situation, the gas pressure is essential since the airflow from the compressed air with $0.0345 \mathrm{MPa}$ pressure assists in maintaining the ideal gap distance between the electrodes (workpiece and wire electrode). The gap distance allows the phenomenon of breakdown voltage to occur which leads to the formation of microplasma [30, 33, 35]. Hence, compressed air as dielectric fluid would be the best choice for a stable machining since there is a continuous airflow with the $0.0345 \mathrm{MPa}$ pressure at the machining area compared to the atmospheric air.

\subsection{Dielectric fluid pressure}

In the DEDM process, it is essential to determine the pressure of gas during the machining process since it affects the formation of microplasma $[30,33,35]$. Figure 3 shows the graph of machining length with respect to gap voltage for dielectric fluid pressure. The $\mu$ DWEDM process was very unstable when $0.0609 \mathrm{MPa}$ and $0.1034 \mathrm{MPa}$ were used as the dielectric fluid pressure. This is caused by the wire breakage that happens during the machining process which halts the machining operation. The wire breaks whenever the machining process
Fig. 3 Graph of machining length with respect to gap voltage for dielectric fluid pressure as indicated by the legend. $(10 \mathrm{nF}$ capacitance, $24 \%$ threshold voltage, compressed air as dielectric fluid, workpiece positive polarity, $0.2 \mu \mathrm{m} / \mathrm{s}$ wire feed rate, $0.0809 \mathrm{~N}$ wire tension, and $0.5 \mathrm{rpm}$ wire speed)

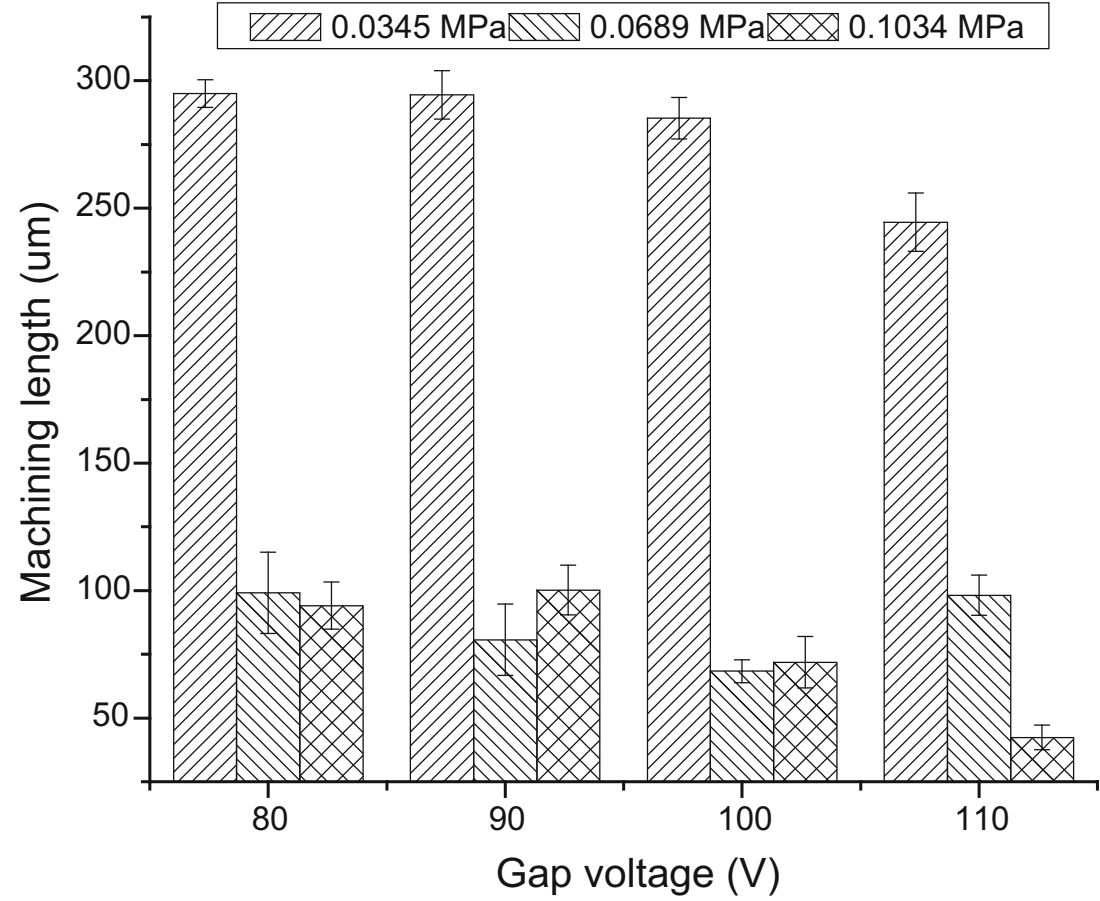


continues further than the machining length, machining length $<125 \mu \mathrm{m}$ (Fig. 3). Aside from the wire breakage, severe thermal damage also happens on the workpiece surface which is due to the arcing phenomenon: harmful discharges that lead to an unstable machining operation, excessive electrode wear, and thermal damage on the workpiece and electrode surfaces [10]. However, from Fig. 3, when $0.0345 \mathrm{MPa}$ dielectric fluid pressure is used, the machining process is much more stable (machining length $\geq 225 \mu \mathrm{m}$ ) with intact wire. It is due to the formation of the micro-breakdown mechanism which is influenced by the gap distance between the electrodes $(d)$ as stated by the modified Paschen's law [28-34] (Subsection 3.1). When modified Paschen's law is applied in micro-breakdown mechanism, then ion-enhanced field emission plays a crucial role in generating the microplasma $[10$, 28]. Ion-enhanced field emission reacts as an additional electron source to the microplasma through the new field emission-driven microdischarges; massive amount of electrons are supplied from the field emission instead of ionization or secondary emission $[29,36-40]$. Furthermore, electric field, $E$ is the main reason for the deviation of the Paschen's law where it influences the electron emission $[10,29,30,35$, $38,41]$. As inferred in the previous subsection, even though the dielectric fluid pressure is a necessity during the machining operation to sustain the gap distance between the electrodes, the ideal dielectric fluid pressure for the compressed air in $\mu$ DWEDM would be $0.0345 \mathrm{MPa}$.

\subsection{Polarity}

Polarity is a vital parameter where it has substantial implications on stability of the machining operation [10, 42]. Figure 4 shows the graph of machining length with respect to gap voltage for several combinations of dielectric fluid and workpiece polarity. Based on the figure, stable machining operation is attainable when the workpiece polarity is positive with compressed air as the dielectric fluid (machining length $\geq$ $150 \mu \mathrm{m})$. This situation is explainable by the occurrence of the hot anode vacuum arcs (HAVA) at the machining area [10]. Micro-breakdown mechanism (subsection 3.2) explained by the modified Paschen's law is actually similar to the vacuum breakdown when the gap distance between the electrodes is less than $5 \mu \mathrm{m}[30,34,38,41,43]$. The phenomenon is caused by the electrons from the field emission [10, $30,38,41]$. Thus, ion-enhanced field emission escalates the generation of microplasma [28]. This brief explanation justifies the formation of the $\mu \mathrm{DWEDM}$ microplasmas that lead to the formation of a specific type of vacuum discharge known as HAVA [10, 30, 33-35]. Hence, the workpiece as the positive polarity while the wire electrode as the negative polarity would be the best option for a stable and smooth machining operation.

\subsection{Threshold voltage}

Threshold voltage is a minimum voltage that initiates the breakdown mechanism in order to form discharges [44]. Figure 5 shows the graph of machining length with respect to gap voltage for threshold voltage. Based on the figure, 24\% threshold voltage is capable in producing the longest microchannels, $\geq 275 \mu \mathrm{m}$, using $\mu \mathrm{DWEDM}$ compared to $23 \%$ and $25 \%$. These results are explainable by the gap distance between the electrodes, $d$, as stated by the modified Paschen's law, micro-breakdown phenomenon (Subsections
Fig. 4 Graph of machining length with respect to gap voltage for several combinations of dielectric fluid and workpiece polarity as indicated by the legend. ( $1 \mathrm{nF}$ capacitance, $24 \%$ threshold voltage, $0.2 \mu \mathrm{m} / \mathrm{s}$ wire feed rate, $0.0809 \mathrm{~N}$ wire tension, and $0.5 \mathrm{rpm}$ wire speed. The pressure for the compressed air was $0.0345 \mathrm{MPa})$

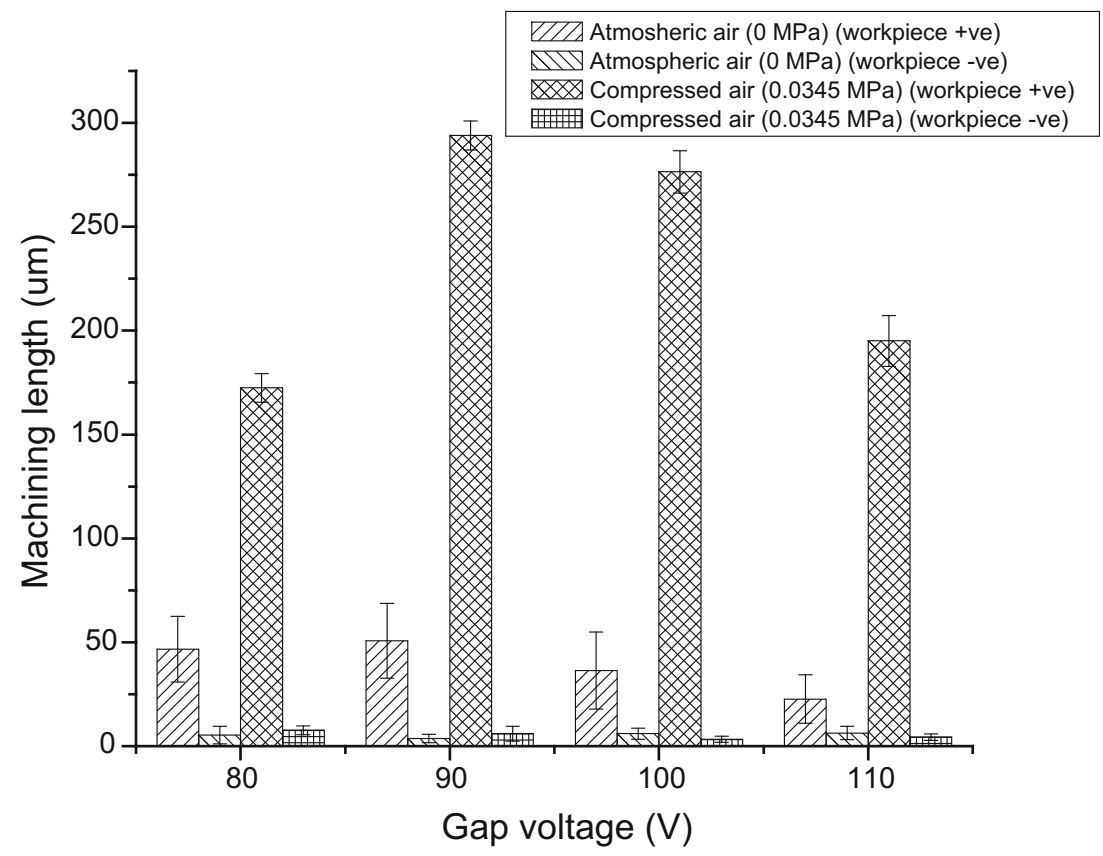


Fig. 5 Graph of machining length with respect to gap voltage for threshold voltage as indicated by the legend. ( $1 \mathrm{nF}$ capacitance, compressed air as dielectric fluid, $0.0345 \mathrm{MPa}$ dielectric fluid pressure, workpiece positive polarity, $0.2 \mu \mathrm{m} / \mathrm{s}$ wire feed rate, $0.0809 \mathrm{~N}$ wire tension, and $0.6 \mathrm{rpm}$ wire speed)

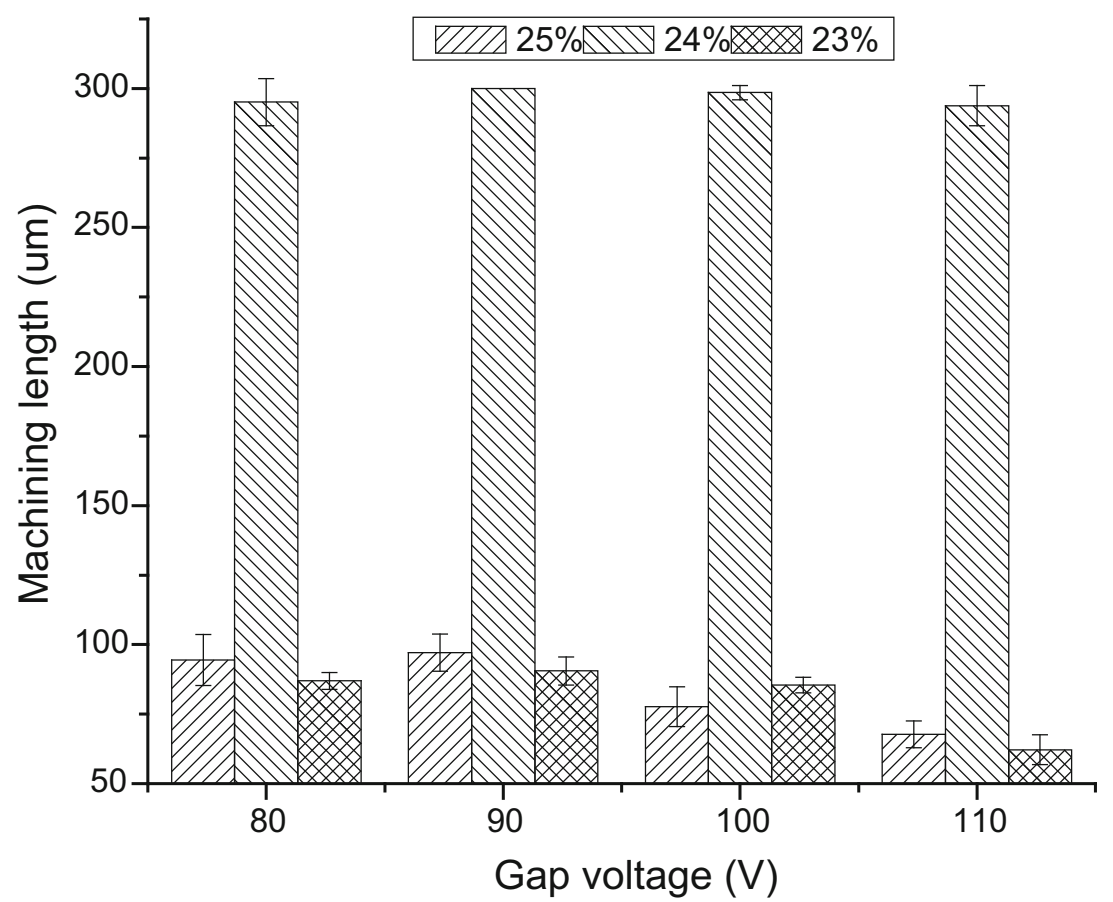

3.1 and 3.2). When the gap distance between the electrodes is less than $5 \mu \mathrm{m}$ and the voltage used is less than $300 \mathrm{~V}$, the formation of microplasma is possible [10, 34, 43] which is the same as this situation. For this case, it is assumed that the gap distance between the electrodes is less than $5 \mu \mathrm{m}$ since the gap voltage used is less than $110 \mathrm{~V}$. Since the micro-breakdown mechanism is identical to the vacuum breakdown, ionenhanced field emission (Subsection 3.3) in micro gaps is initiated due to the rapid fall of the breakdown voltage and the decrement of the gap distance [30, 33, 35, 38]. Hence, $24 \%$ of threshold voltage is the best option for a stable machining process. But the value of the threshold voltage varies depending on the type of gas used since the micro-breakdown mechanism differs based on different types of gas composition used.

\subsection{Wire tension}

Wire tension controls the tension of the wire between the upper and lower wire guides where it influences the wire vibration, wire lag, and wire breakage during the machining process [45-47]. Figure 6 shows the graph of machining length with respect to gap voltage for wire tension. Based on the figure, stable and smooth machining with high amount of material removal (machining length $\geq 250 \mu \mathrm{m}$ ) is achievable when $0.0809 \mathrm{~N}$ wire tension is used. However, wire breakage frequently occurred when $0.1214 \mathrm{~N}$ wire tension was used (machining length $\leq 125 \mu \mathrm{m}$ ). Normally, high wire tension reduces wire vibration $[25,48]$, but in this case, the results are vice versa [10]. The reason behind this circumstance is due to the forces acting on the wire during the machining process. The forces are the reaction forces generated from the pressure of the gas bubbles during the erosion mechanism, hydrodynamic forces from the flushing system, the electrostatic forces that act on the wire, and the electromagnetic forces from the spark generation [10, 45, 49, 50]. However, the reaction force is negligible since the machining process was done in dry condition. It is because no gas bubbles were generated during the erosion mechanism [10, 15, 25, 34]. In addition, wire breakage may also occur due to high amount of stresses developed in wire [47]. Thus, for this study, stable and smooth machining process is achievable when $0.0809 \mathrm{~N}$ wire tension is used.

\subsection{Wire feed rate}

Results for the wire feed rate are shown in Fig. 7, graph of machining length with respect to gap voltage for wire feed rate. Based on the figure, stable and smooth $\mu$ DWEDM is possible to achieve if $0.2 \mu \mathrm{m} / \mathrm{s}$ wire feed rate is used where the machining lengths are more than $200 \mu \mathrm{m}$. However, the results are opposing when $0.4 \mu \mathrm{m} / \mathrm{s}$ wire feed rate was used. The wire electrode would easily break during the machining process whenever the discharges are generated in the inter-electrode gap. In this situation, the gap distance between the electrodes gradually deteriorates causing wire breakage $[10,51]$. Hence, it affects the microbreakdown mechanism as per mentioned by the modified Paschen's law (subsection 3.1 and 3.2). Although the wire does not break immediately, but the gap remains deteriorated until the wire breaks [51]. Besides that, wire breakage may easily occur when the shape of the wire changes due to the formation of the unwanted discharges between the unflushed debris and the wire 
Fig. 6 Graph of machining length with respect to gap voltage for wire tension as indicated by the legend. (10 $\mathrm{nF}$ capacitance, compressed air as dielectric fluid, $0.0345 \mathrm{MPa}$ dielectric fluid pressure, workpiece positive polarity, $24 \%$ threshold voltage, $0.2 \mu \mathrm{m} / \mathrm{s}$ wire feed rate, and $0.6 \mathrm{rpm}$ wire speed)

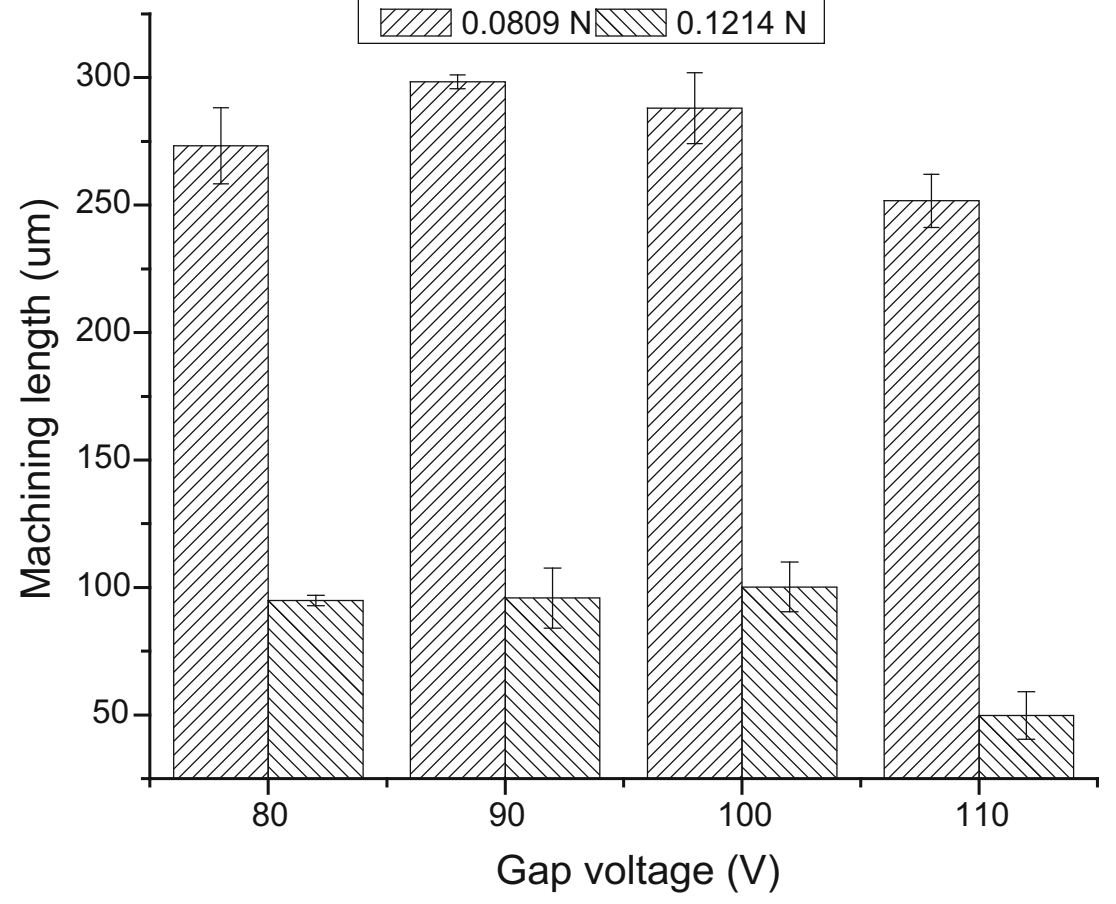

electrode [52]. Therefore, for a stable and smooth machining process, it is proposed to use $0.2 \mu \mathrm{m} / \mathrm{s}$ wire feed rate.

\subsection{Wire speed}

One of the ways to controlled wire wear or wire breakage is by controlling the wire speed [53]. Figure 8 shows the graph of machining length with respect to gap voltage for wire speed. Based on the graph, when $0.6 \mathrm{rpm}$ wire speed is applied, higher amount of material is removed (machining length $\geq 220 \mu \mathrm{m}$ ) during the machining operation compared to $0.5 \mathrm{rpm}$ wire speed (machining length $\leq 100 \mu \mathrm{m}$ ). Moreover, when $0.5 \mathrm{rpm}$ wire speed was used, the wire would easily break off during the machining process. Actually, in $\mu$ DWEDM, the material removal mechanism happens in both of the electrodes, wire electrode, and workpiece [10, 26]. When small amount of materials is removed from the wire, it causes the wire to wear resulting in wire breakage. It is due to the higher amount of stress developed in the wire compared to the wire strength $[10,47]$. So, as a resolution, $0.6 \mathrm{rpm}$ wire speed is proposed to be used during the machining

Fig. 7 Graph of machining length with respect to gap voltage for wire feed rate as indicated by the legend. ( $1 \mathrm{nF}$ capacitance, $24 \%$ threshold voltage, compressed air as dielectric fluid, $0.0345 \mathrm{MPa}$ dielectric fluid pressure, workpiece positive polarity, $0.0809 \mathrm{~N}$ wire tension, and $0.5 \mathrm{rpm}$ wire speed)

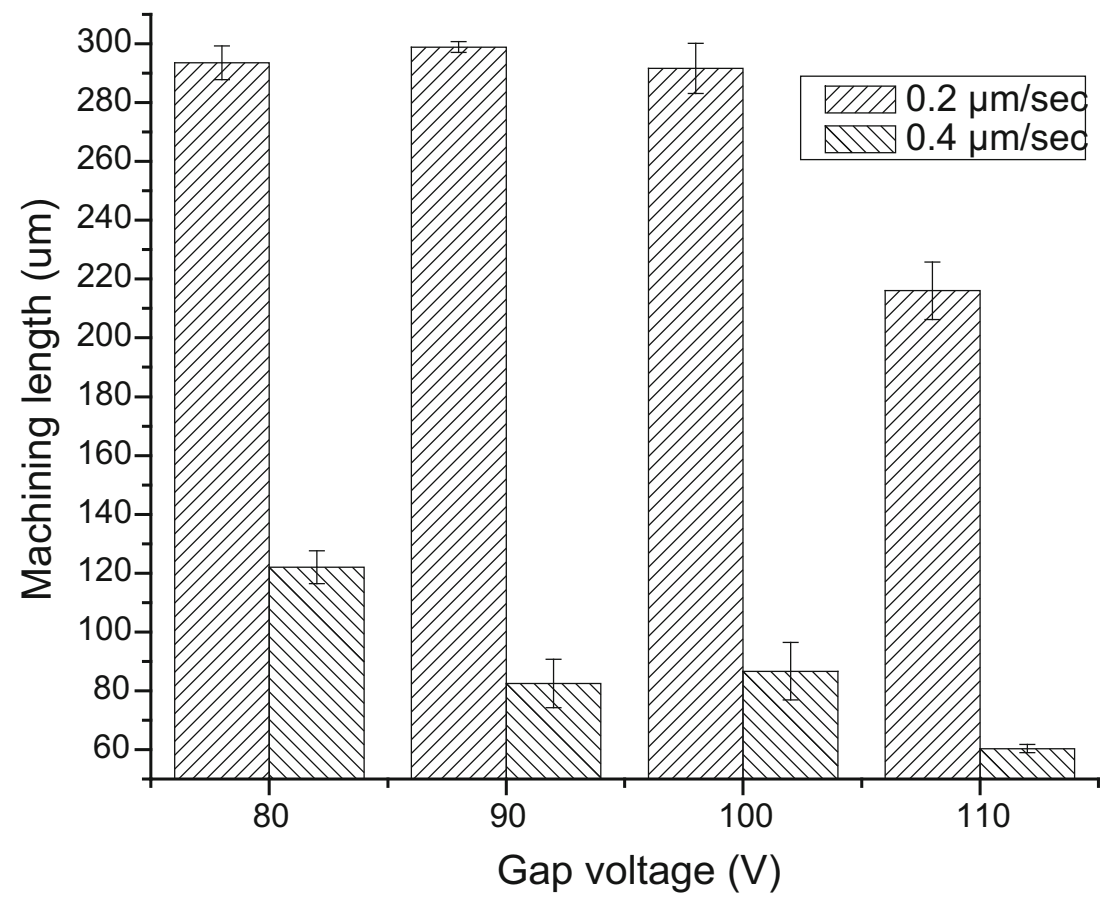


Fig. 8 Graph of machining length with respect to gap voltage for wire speed as indicated by the legend. $(0.10 \mathrm{nF}$ capacitance, $24 \%$ threshold voltage, compressed air as dielectric fluid, $0.0345 \mathrm{MPa}$ dielectric fluid pressure, workpiece positive polarity, $0.0809 \mathrm{~N}$ wire tension, and $0.2 \mu \mathrm{m} / \mathrm{s}$ wire feed rate)

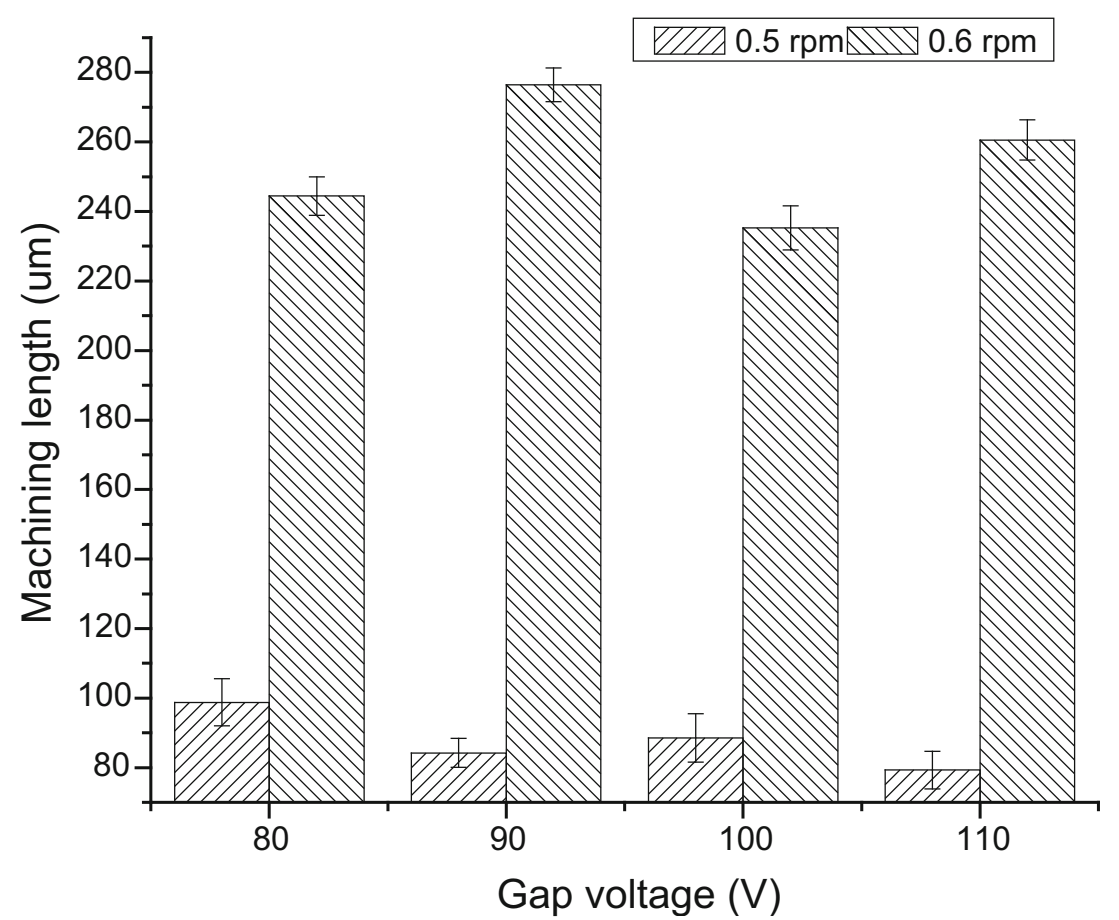

operation because new wire is continuously supplied for a smooth and stable machining process.

\subsection{Capacitance}

Figure 9 shows the graph of machining length with respect to gap voltage for capacitance. Based on the figure, when $100 \mathrm{nF}$ and
$0.01 \mathrm{nF}$ are used, the material removed during the machining operation is small (machining length $\leq 150 \mu \mathrm{m}$ ). Also, when $100 \mathrm{nF}$ capacitance is used, wire breakage would occur during the machining operation. Higher amount of capacitance has the ability in producing higher discharge energy where stronger sparks are generated to erode more material. Due to the high amount of material erosion, the unflushed debris was trapped at
Fig. 9 Graph of machining length with respect to gap voltage for capacitance as indicated by the legend. (24\% threshold voltage, compressed air as dielectric fluid, $0.0345 \mathrm{MPa}$ dielectric fluid pressure, workpiece positive polarity, $0.0809 \mathrm{~N}$ wire tension, $0.2 \mu \mathrm{m} / \mathrm{s}$ wire feed rate, and $0.6 \mathrm{rpm}$ wire speed)

\section{VIIA $100 \mathrm{nR} 1 \mathrm{~A} 10 \mathrm{nF} 0.10 \mathrm{nFm} 0.01 \mathrm{nF}$}

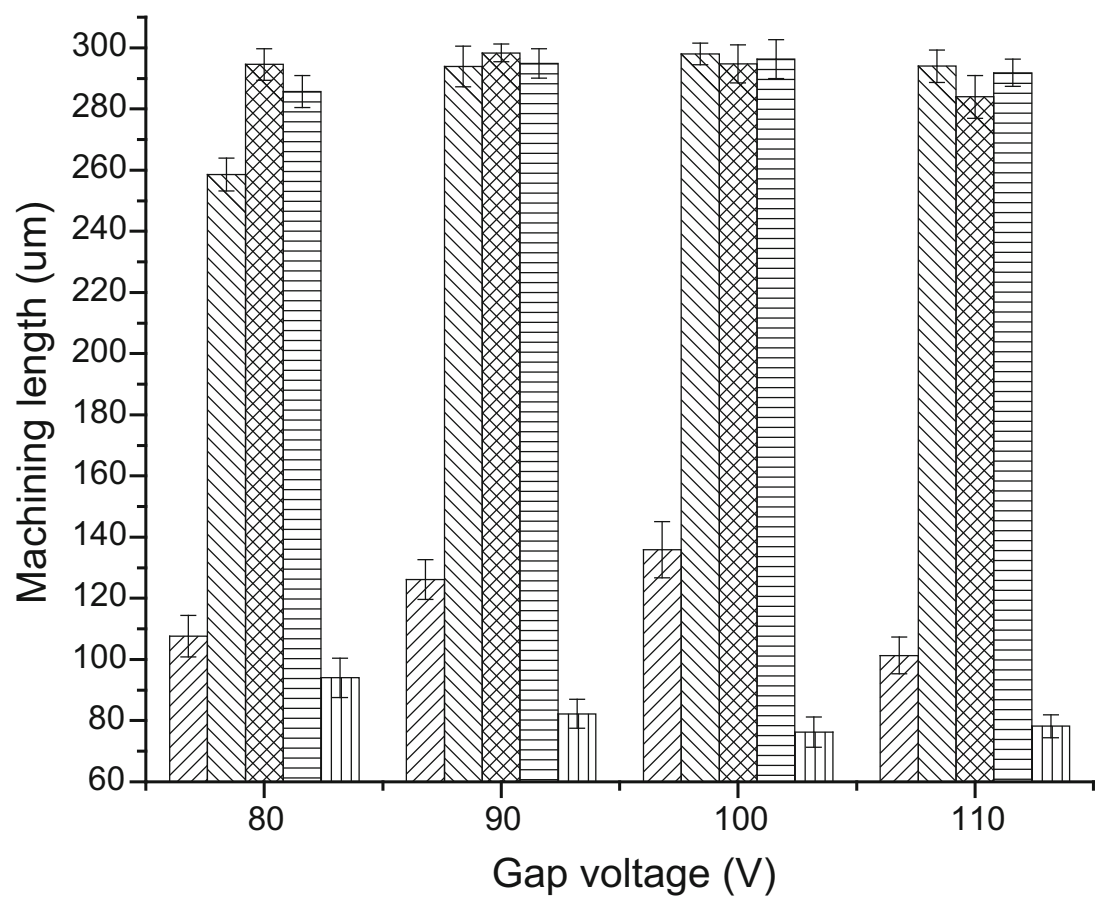


the inter-electrode gap causing unwanted discharges between the tool and the debris. Consequently, small amount of material is removed from the workpiece $[10,52]$. Additionally, higher discharge energy increases the wire vibration which may cause wire breakage [25]. On the other hand, when too small capacitance $(0.01 \mathrm{nF})$ is utilised, the discharge energy produced is not sufficient to generate the micro-breakdown voltage mechanism [10]. Hence, for smooth and stable machining, it is suggested to use capacitance of $10 \mathrm{nF}, 1.00 \mathrm{nF}$, and $0.10 \mathrm{nF}$.

\subsection{Gap voltage}

As for the gap voltage, smooth and stable machining operation is achievable for all the varied values as shown in Fig. 10, graph of machining length with respect to gap voltage. The machining length for these gap voltages was more than $280 \mu \mathrm{m}$. It is due to the formation of microplasma which involves the micro-breakdown mechanism (Subsections 3.2, 3.3, and 3.4). The mechanism occurs when there is a sufficiently high electric field to accelerate the electrons [10, 28, $33,36]$. Usually, gap voltage influences the formation of the electric field $[10,54,55]$. Hence, smooth and stable machining process is possible for all the values, $80 \mathrm{~V}, 90 \mathrm{~V}, 100 \mathrm{~V}$, and $110 \mathrm{~V}$, of the gap voltage.

\section{Results and analysis for Plackett-Burman design}

Plackett-Burman design is used to statistically validate the results of the OFAT method. The results of the experiments are analysed statistically using analysis of variance (ANOVA). Initially, a half-normal plot of effects (Fig. 11) was selected in order to find the significant effects of the factors [56]. Based on the figure, $A$ (dielectric fluid), $B$ (dielectric fluid pressure), $C$ (workpiece polarity), $H$ (capacitance), and $J$ (gap voltage) are the factors that were selected as the significant main effects since the percentage contribution is more than $5 \%$. As a result, these factors would be further analysed using ANOVA in order to check the adequacy of the developed statistical model [25].

The developed model in terms of coded factors is presented by Eq. 1 where $l=$ machining length $(\mu \mathrm{m}), A=$ dielectric fluid, $B=$ dielectric fluid pressure, $C=$ workpiece polarity, $H=$ capacitance, and $J=$ gap voltage. The developed model using coded factors is desirable since it helps determine the most significant factors that have an effect on the response [20].

$$
\begin{aligned}
l= & 31.06+19.69 A-9.85 B+27.25 C \\
& +11.08 H-10.98 J
\end{aligned}
$$

In order to ascertain the significance of the developed model, the machining length for high and low parameters was calculated using Eq. 1 [57]. From the calculation, it was found that the machining length for high, $l_{\text {high }}$, and low, $l_{\text {low }}$ coded parameters are $68.25 \mu \mathrm{m}$ and $-6.13 \mu \mathrm{m}$ respectively $\left(l_{\text {high }}=\right.$ $68.25 \mu \mathrm{m}$ and $\left.l_{\text {low }}=-6.13 \mu \mathrm{m}\right)$. The positive value of machining length for high coded parameters indicates that there is a machining process between the wire electrode and the workpiece. Meanwhile, the negative value of the machining length for low-coded factors shows that the machining process
Fig. 10 Graph of machining length with respect to gap voltage. ( $1 \mathrm{nF}$ capacitance, $24 \%$ threshold voltage, compressed air as dielectric fluid, $0.0345 \mathrm{MPa}$ dielectric fluid pressure, workpiece positive polarity, $0.0809 \mathrm{~N}$ wire tension, $0.2 \mu \mathrm{m} / \mathrm{s}$ wire feed rate, and $0.5 \mathrm{rpm}$ wire speed)

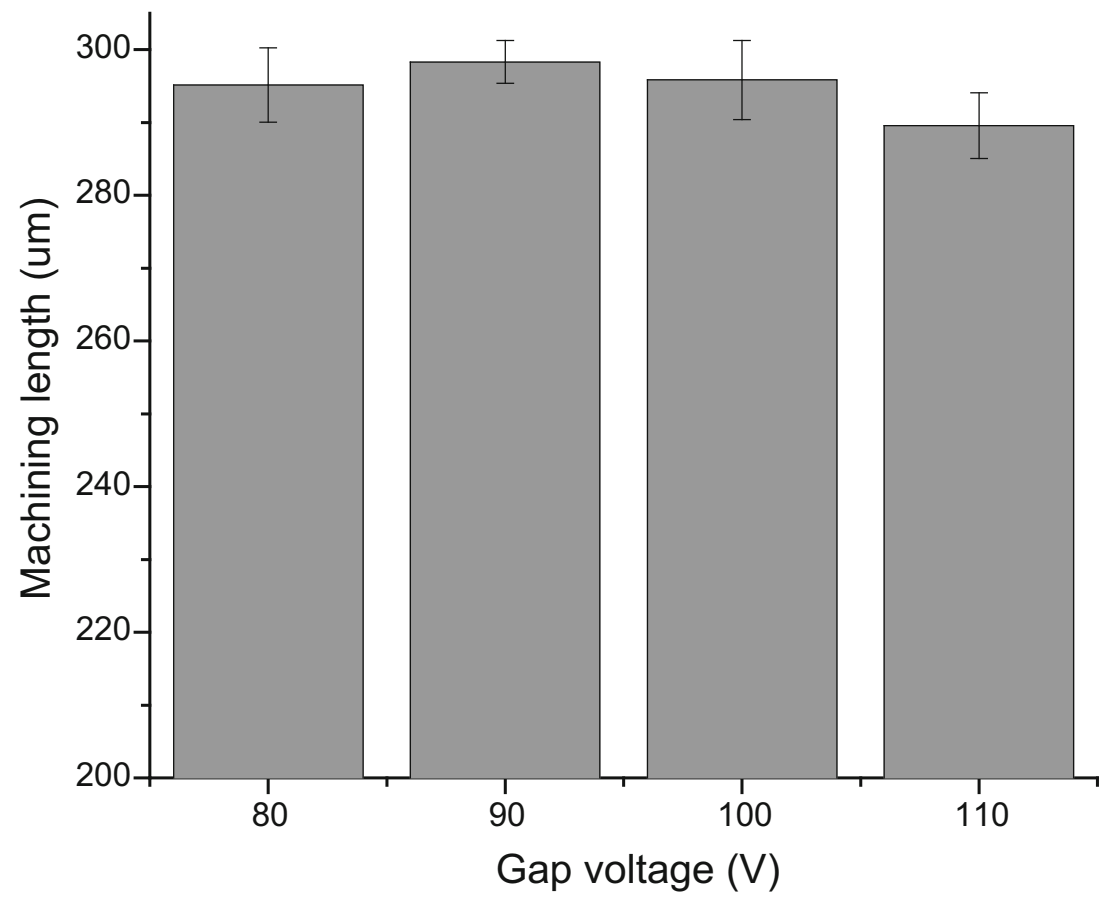


Fig. 11 Half-normal plot of effects. ( $A=$ dielectric fluid, $B=$ dielectric fluid pressure, $C=$ workpiece polarity, $H=$ capacitance, and $J=$ gap voltage)

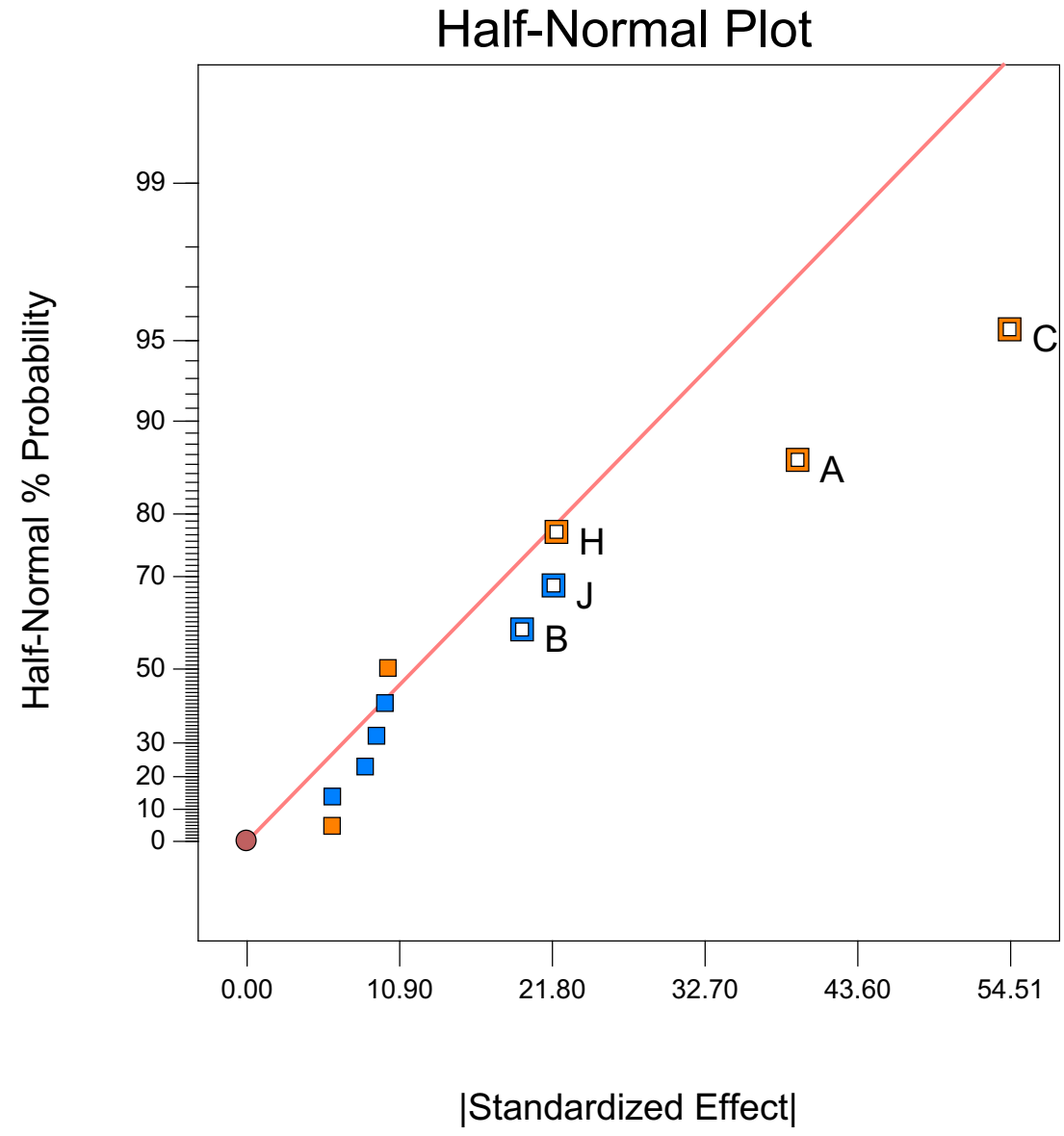

between the wire electrode and the workpiece is interrupted. Thus, it proves that the developed model is significant.

Table 4 presents the statistical analysis using ANOVA for Plackett-Burman design. The model $F$-value of 16.22 implies that the model was significant at high level of confidence [25]. The significance of the model is also clarified by the relatively low value of Prob $>F, 0.0020$. The $F$-value is statistically valid because it measures on how well the factors describe the variation in the mean of data. Higher $F$-value implies that the estimated factor effects are real since the factors are able to explain adequately the variation in the data especially related to its mean. In general, the $F$-value is inversely proportional to Prob > $F$ [58]. From the table, it is observed that the most significant factor would be $C$ (workpiece polarity) with Prob $>F$ of 0.0007 followed by $A$ (dielectric fluid), $H$ (capacitance), and $J$ (gap voltage). As for factor $B$ (dielectric fluid pressure), the value of
Table 4 ANOVA for PlackettBurman design

\begin{tabular}{lcclrl}
\hline Source & Sum of squares & DF & Mean square & $F$-value & Prob $>F$ \\
\hline Model & $17,646.76$ & 5 & 3529.35 & 16.22 & 0.0020 \\
$A-$ Dielectric fluid & 4650.52 & 1 & 4650.52 & 21.37 & 0.0036 \\
$B-$ Dielectric fluid pressure & 1164.93 & 1 & 1164.93 & 5.35 & 0.0599 \\
$C-$ Workpiece polarity & 8912.57 & 1 & 8912.57 & 40.96 & 0.0007 \\
$H-$ Capacitance & 1473.34 & 1 & 1473.34 & 6.77 & 0.0405 \\
$J-$ Gap voltage & 1445.41 & 1 & 1445.41 & 6.64 & 0.0419 \\
Residual & 1305.41 & 6 & 217.57 & & \\
Corrected total & $18,952.18$ & 11 & & & 0.9311 \\
Standard deviation & & 14.75 & $R^{2}$ & & 0.8737 \\
Mean & & 31.06 & Adjusted $R^{2}$ & & 0.7245 \\
Coefficient of variation & 47.49 & Predicted $R^{2}$ & & 9.236 \\
Predicted residual error of sum of square & 5221.66 & Adequate precision \\
\hline
\end{tabular}




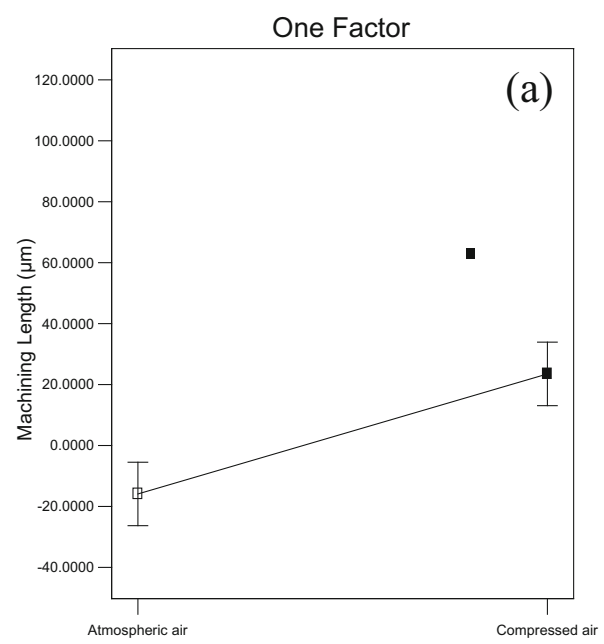

A: Dielectric Fluid

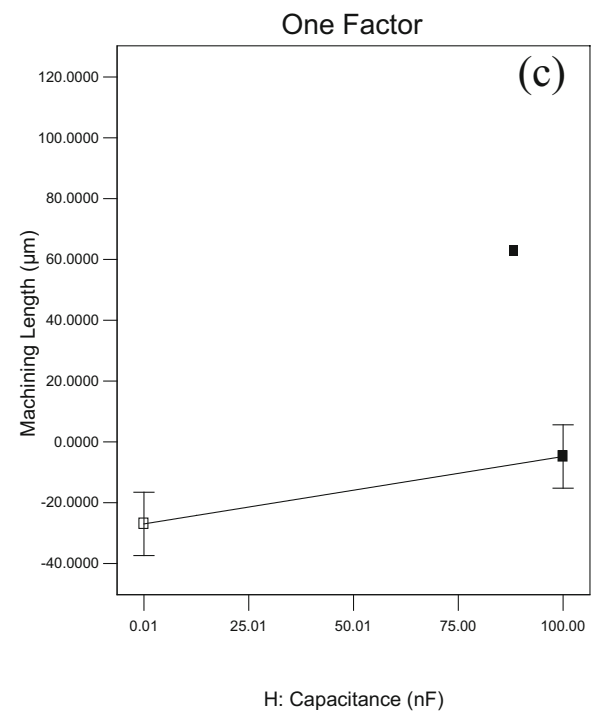

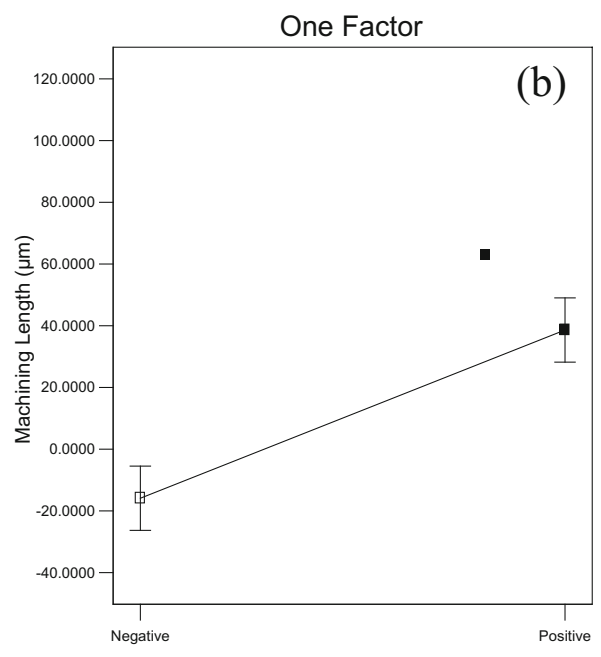

C: Workpiece Polarity

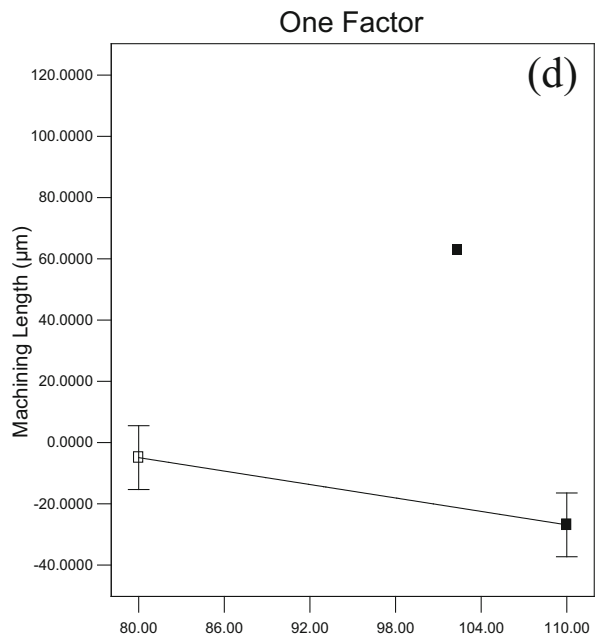

J: Gap Voltage (V)

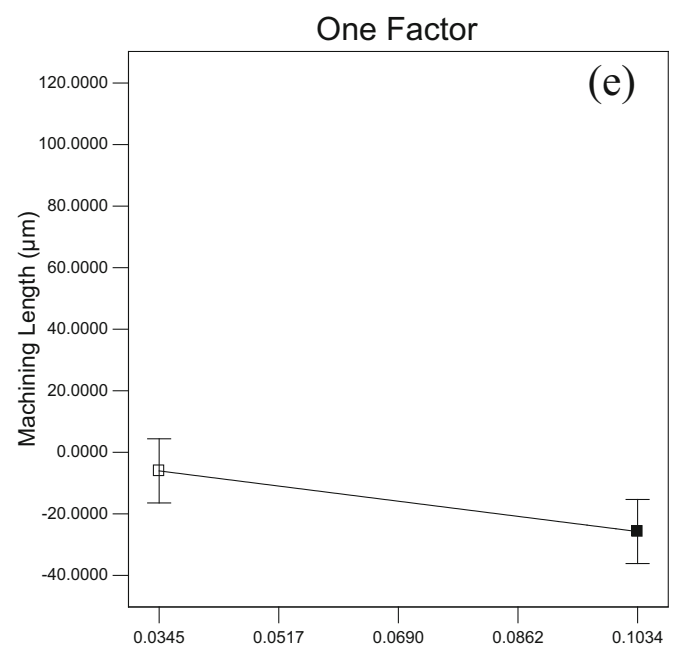

B: Dielectric Fluid Pressure (MPa)

Fig. 12 Main effects plot for a dielectric fluid vs. machining length, b workpiece polarity vs. machining length, $\mathbf{c}$ capacitance vs. machining length, d gap voltage vs. machining length, and e dielectric fluid pressure vs. machining length 
Prob $>F, 0.0599$, indicates that the factor is insignificant since the Prob $>F$-value is more than 5\% [25].

Moreover, the variability amount of the mean of the data represented by the $R^{2}$ is around 0.9311 . It indicates that $93.11 \%$ of the factors play a vital role in the response. The model is sufficient in explaining most of the variability in the experiment results because the $R^{2}$ value is greater than $0.75[25,59]$. The value of the predicted $R^{2}$ is in reasonable agreement with the value of the adjusted $R^{2}$ since the difference is around $0.15[25,60]$. As for the signal-to-noise ratio expressed through the adequate precision, 9.236 shows that the signal is tolerable since the value is greater than 4 . Therefore, this model can be used to navigate the design space $[58,60]$. Hence, based on these statistical characteristics, it can be concluded that the model is adequate to determine the main effects of the factors.

Figure 12 shows the main effect plots of the statistically significant factors. The graphs were used to estimate the values of the significant factors in order to achieve a maximum machining length. The results suggested that maximum machining length is achievable when compressed air is used as the dielectric fluid (factor $A$ ), positive polarity is used as the workpiece polarity (factor $C$ ), capacitance (factor $H$ ) is set at higher value, gap voltage (factor $J$ ) is set at lower value, and $0.0345 \mathrm{MPa}$ is used as the dielectric fluid pressure (factor $B$ ). As a result, the strength of each of the factors could be ascertained [27] based on this statistical analysis.

\section{Conclusion}

In this research, $\mu$ DWEDM was presented as a prospective fabrication technique to produce structures with high accuracy and precision. The parameters involved were types of dielectric fluid, dielectric fluid pressure, polarity, threshold voltage, wire tension, wire feed rate, wire speed, gap voltage, and capacitance. The stability of $\mu$ DWEDM was determined using two different experimental approaches which were conventional experimental method, OFAT, and statistical experimental method, PlackettBurman design. Plackett-Burman design was used to verify the results obtained from the conventional method. This research showed:

1. Types of dielectric fluid, dielectric fluid pressure, workpiece polarity, threshold voltage, wire tension, wire feed rate, wire speed, gap voltage, and capacitance are the parameters that have been identified using OFAT and DOE methods for uninterrupted, stable, and smooth $\mu$ DWEDM process. Smooth and stable $\mu$ DWEDM process previously was impossible to achieve since the parameters and their levels were unknown where it hinders the industrial applications. This investigation eventually opens the door for $\mu \mathrm{DWEDM}$ to be implemented in the industrial sector.

2. Based on the OFAT method, the results revealed that stable and smooth machining operation is achievable when compressed air is used as the dielectric fluid, $0.0345 \mathrm{MPa}$ dielectric fluid pressure, workpiece positive polarity, $24 \%$ threshold voltage, $0.0809 \mathrm{~N}$ wire tension, $0.2 \mu \mathrm{m} / \mathrm{s}$ wire feed rate, and $0.6 \mathrm{rpm}$ wire speed. As for the capacitance, smooth and stable machining operation is attainable when $10 \mathrm{nF}, 1.00 \mathrm{nF}$, and $0.10 \mathrm{nF}$ are used. Meanwhile, for the gap voltage, all the values are applicable in producing a stable and smooth machining operation without breaking the wire electrode. Therefore, it is proposed that the capacitance $(10 \mathrm{nF}, 1.00 \mathrm{nF}$, and $0.10 \mathrm{nF})$ and the gap voltage $(80 \mathrm{~V}, 90 \mathrm{~V}, 100 \mathrm{~V}$, and $110 \mathrm{~V})$ are the factors that should be considered for further investigation.

3. Placket-Burmann design was used to validate statistically the results obtained using the OFAT method. Based on the results, it was found that dielectric fluid, workpiece polarity, capacitance, gap voltage, and dielectric fluid pressure have significant effects on the machining length. It means that a smooth and stable machining operation is achievable by controlling these five factors. However, for the experimentation purposes, the selection of the dielectric fluid, dielectric fluid pressure, and polarity should remain as the fixed parameters, compressed air as dielectric fluid, $0.0345 \mathrm{MPa}$ dielectric fluid pressure, and workpiece positive polarity, in order to achieve a smooth and stable machining operation. This means that wire rupture can be avoided during the machining operation. Therefore, the results of the validation are similar to the results of the OFAT method where capacitance and gap voltage should be employed for further investigation.

4. In the field of micromachining, $\mu$ DWEDM is still a new research area. Therefore, there are no extensive research outcomes that have been reported. Hence, reference for comprehensive benchmarking is unavailable. The findings are benchmarked with Hoang and Yang [61], Macedo et al. [35], and Macedo et al. [62].

Acknowledgements The authors are thankful to the faculty and staff of the Micromanufacturing laboratory and Metallographic laboratory at IIUM for their support.

Funding information This research was funded by MOSTI under Research Grant SF15-016-0066.

\section{References}

1. Liao YS, Chen ST, Lin CS (2005) Development of a high precision tabletop versatile $\mathrm{CNC}$ wire-EDM for making intricate micro parts. J Micromech Microeng 15:245-253 
2. Yoo HK, Kwon WT, Kang S (2014) Development of a new electrode for micro-electrical discharge machining $(\mathrm{EDM})$ using $\mathrm{Ti}(\mathrm{C}$, N)-based cermet. Int J Precis Eng Manuf 15(4):609-616

3. Hoang KT, Yang SH (2013) A study on the effect of different vibration-assisted methods in micro-WEDM. J Mater Process Technol 213:1616-1622

4. Hoang KT, Yang SH (2015) A new approach for micro-WEDM control based on real-time estimation of material removal rate. Int $\mathbf{J}$ Precis Eng Manuf 16(2):241-246

5. Debroy A, Chakraborty S (2013) Non-conventional optimization techniques in optimizing non-traditional machining processes: a review. Manag Sci Lett 3(1):23-38

6. Yan MT (2010) An adaptive control system with self-organizing fuzzy sliding mode control strategy for micro wire-EDM machines. Int J Adv Manuf Technol 50:315-328

7. Pour GT, Pour YT, \& Ghoreishi M (2014) Electro-spark nanomachining process simulation. Int J Mater Mech Manuf, 2 (1)

8. Pour GT, Pour YT, Ghoreishi M (2014) Thermal model of the electro-spark nanomachining process. Int J Mater Mech Manuf 2(1):56-59

9. Banu A, Ali MY (2016) Electrical discharge machining (EDM): a review. Int J Eng Mater Manuf 1(1):3-10

10. Banu A, Ali MY, Rahman MA, Konneh M (2019) Investigation of process parameters for stable micro dry wire electrical discharge machining. Int J Adv Manuf Technol 103(1-4):723-741

11. Azhiri RB, Teimouri R, Baboly MG, Laseman Z (2014) Application of Taguchi, ANFIS and grey relational analysis for studying, modelling and optimization of wire EDM process while using gaseous media. Int J Adv Manuf Technol 71(1):279-295

12. Pandey A, Singh S (2010) Current research trends in variants of electrical discharge machining: a review. Int J Eng Sci Technol 2(6): 2172-2191

13. Ali MY, Banu A, Rahman MA, Hazza M, Adesta EYT (2018) Precision control of kerf in metal cutting using dry micro WEDM: issues and challenges. Key Eng Mater 775:49-505

14. Leao FN, Pashby IR (2004) A review on the use of environmentally-friendly dielectric fluids in electrical discharge machining. J Mater Process Technol 149:341-346

15. Ghodsiyeh D, Moradi M (2015) Wire electrical discharge machining. In: Jahan MP (ed) Electrical discharge machining (EDM) types, technologies and applications. Nova Science Publishers, Inc., New York, pp 33-65

16. Wani YB, Patil DD (2017) An experimental design approach for optimization of spectrophotometric method for estimation of cefixime trihydrate using ninhydrin as derivatizing reagent in bulk and pharmaceutical formulation. J Saudi Chem Soc 21:S101-S111

17. Wahid Z, Nadir N (2013) Improvement of one factor at a time through design of experiments. World Appl Sci J 21:56-61

18. McDonald GC \& Gunst RF (1991) Issues involved in the choice of experimental design strategies (Technical Report No. SMU/DS/TR/ 253). Department of Statistical Science, Southern Methodist University

19. Xu H, Phoa FK, Wong WK (2009) Recent developments in nonregular fractional factorial designs. Stat Surv 3:18-46

20. Montgomery DC (2005) Design and analysis of experiments, 6th edn. John Wiley and Sons, Inc.

21. Stowe RA, Mayer RP (1966) Efficient screening of process variables. Ind Eng Chem 58(2):36-40

22. Dejaegher B, Capron X, Smeyers-Verbeke J, Vander Heyden Y (2006) Randomization tests to identify significant effects in experimental designs for robustness testing. Anal Chim Acta 564(2): 184-200

23. No AMCTB, Committee AM (2013) Experimental design and optimization (4): Plackett-Burman designs. Anal Methods 5(8):19011903
24. Ali MY, Banu A, Shaffiq M, Rahman MA, Konneh M, Salehan M (2019) Investigation of taper angle in dry micro wire EDM. Int J Mech Eng Robot Res 8(1):725-728

25. Ali MY, Banu A, Salehan M, Adesta EYT, Hazza M, Shaffiq M (2018) Dimensional accuracy in dry micro wire electrical discharge machining. J Mech Eng Sci 12(1):3321-3329

26. Maher I, Sarhan AAD, Hamdi M (2015) Review of improvements in wire electrode properties for longer working time and utilization in wire EDM machining. Int J Adv Manuf Technol 76:329-351

27. Ndaliman MB, Khan AA, Ali MY, Wahid Z (2013) Determination of influential factors on EDMed surface properties using PlackettBurman design. World Appl Sci J 21:88-93

28. Li Y (2014) Analysis of ion-enhanced field emission and field emission-driven microdischarges (doctor of philosophy's dissertation). Notre Dame University, Notre Dame

29. Go DB, Pohlman DA (2010) A mathematical model of the modified Paschen's curve for breakdown in microscale gaps. J Appl Phys 107(10):103303

30. Macedo FTB, Wiessner M, Hollenstein C, Esteves PMB, Wegener $\mathrm{K}$ (2016) Fundamental investigation of dry electrical discharge machining (DEDM) by optical emission spectroscopy and its numerical interpretation. Int J Adv Manuf Technol:1-13

31. Klas M, Matejcik S, Radjenovic B, Radmilovic-Radjenovic M (2011) Experimental and theoretical studies of the breakdown voltage characteristics at micrometer separations in air. EPL (Europhysics Letters) 95(3):35002

32. Dhariwal RS, Torres JM, Desmulliez MPY (2000) Electric field breakdown at micrometer separations in air and nitrogen at atmospheric pressure. IEE Proc Sci Meas Technol 147(5):261-265

33. Radmilovic-Radjenovic M, Radjenovic B (2017) The effect of the field emission on the breakdown voltage characteristics of nitrogen microdischarges. Int J Eng Innov Res 6(6):280-283

34. Wiessner M, Macedo FTB, Martendal CP, Kuster F, Wegener K (2018) Fundamental investigation of EDM plasmas, part I: a comparison between electric discharges in gaseous and liquid dielectric media. Procedia CIRP 68:330-335

35. Macedo FTB, Wiessner M, Hollenstein C, Kuster F, Wegener K (2016) Investigation of the fundamentals of tool electrode wear in dry EDM. Procedia CIRP 46:55-58

36. Tan X, Go DB (2018) Understanding the scaling of electron kinetics in the transition from collisional to collisionless conditions in microscale gas discharges. J Appl Phys 123(6):063303

37. Li Y, Tirumala R, Rumbach P, Go DB (2013) The coupling of ionenhanced field emission and the discharge during microscale breakdown at moderately high pressures. IEEE Trans Plasma Sci 41(1): 24-35

38. Radmilovic-Radjenovic M, Radjenovic B, Klas M, Bojarov A, Matejcik S (2013) The breakdown mechanisms in electrical discharges: the role of the field emission effect in direct current discharges in microgaps. Acta Physica Slovaca 63(3):105-205

39. Rumbach P, Go DB (2012) Fundamental properties of field emission-driven direct current microdischarges. J Appl Phys 112(10): 103302

40. Rumbach P, Li Y, Martinez S, Twahirwa TJ, Go DB (2014) Experimental study of electron impact ionization in field emission-driven microdischarges. Plasma Sources Sci Technol 23(6):065026

41. Macedo FTB, Wiessner M, Hollenstein C, Kuster F, Wegener K (2016) Dependence of crater formation in dry EDM on electrical breakdown mechanism. Procedia CIRP 42:161-166

42. Munz M, Risto M, Haas R (2016) The phenomenon of polarity in EDM drilling process using water based dielectrics. Procedia CIRP 42:532-536

43. Roth R, Balzer H, Kuster F, Wegener K (2012) Influence of the anode material on the breakdown behavior in dry electrical discharge machining. Procedia CIRP 1:639-644 
44. Jahan MP, Rahman M, Wong YS (2014) Micro-electrical discharge machining (micro-EDM): processes, varieties, and applications. In: Hashmi S, Batalha GF, Thyne CJV, Yilbas B (eds) Comprehensive Materials Processing, vol 11. Elsevier, pp 333-371

45. Ho KH, Newman ST, Rahimifard S, Allen RD (2004) State of the art in wire electrical discharge machining (WEDM). Int J Mach Tools Manuf 44:1247-1259

46. Habib S, Okada A (2016) Experimental investigation on wire vibration during fine wire electrical discharge machining process. Int J Adv Manuf Technol 84(9-12):2265-2276

47. Patel VD, Patel DM, Patel UJ, Patel B, Butani N (2014) Review of wire-cut EDM process on titanium alloy. Int J Eng Res Appl 4(12): $112-121$

48. Xiaobing, F. (2013). Modelling and simulation of crater formation and wire vibration in micro WEDM (doctoral's thesis). National University of Singapore, Singapore

49. Tomura S, Kunieda M (2009) Analysis of electromagnetic force in wire-EDM. Precis Eng 33:255-262

50. Maradia, U. \& Wegener, K. (2015). EDM modelling and simulation. In M. P. Jahan (Ed.). Electrical discharge machining (EDM) types, technologies and applications (pp. 67-121). New York: Nova Science Publishers, Inc.

51. Liao YS, Chu YY, Yan MT (1997) Study of wire breaking process and monitoring of WEDM. Int J Mach Tools Manuf 37(4):555-567

52. Reyad M, Ali MY (2009) Investigation of machining parameters for multiple-response optimization of micro electrodischarge milling. Int J Adv Manuf Technol 43(3-4):264-275

53. Garg RK, Singh KK, Sachdeva A, Sharma VS, Ojha K, Singh S (2010) Review of research work in sinking EDM and WEDM on metal matrix composite materials. Int J Adv Manuf Technol 50(58):611-624
54. Florkowska B, Florkowski M, Roehrich J, Zydron P (2010) Partial discharge mechanism in a non-uniform electric field at higher pressure. IET Sci Meas Technol 5(2):59-66

55. Kuffel, E., Zaengl, W. S., \& Kuffel, J. (2000). High voltage engineering fundamentals (2nd). Oxford: Butterworth-Heinemann

56. Khademi A, Renani NG, Mofarrahi M, Jeddi AR, Yusof NM (2013) The best location for speed bump installation using experimental design methodology. Promet Traffic Transp 25(6):565-574

57. Le Man H, Behera SK, Park HS (2010) Optimization of operational parameters for ethanol production from Korean food waste leachate. Int J Environ Sci Technol 7(1):157-164

58. Bari MN, Alam MZ, Muyibi SA, Jamal P (2009) Improvement of production of citric acid from oil palm empty fruit branches: optimization of media by statistical experimental designs. Bioresour Technol 100(12):3113-3120

59. Omar WW, Nordin N, Mohamed M, Amin NAS (2009) A two-step biodesel production from waste cooking oil: optimization of pretreatment step. J Appl Sci 9(17):3098-3103

60. Banu A, Bakar MA, Ali MY, Adesta EY (2017) Analysis of WEDM process parameters on surface roughness and kerf using Taguchi method. Int J Eng Mater Manuf 2(4):103-109

61. Hoang KT, Yang SH (2015) Kerf analysis and control in dry microwire electrical discharge machining. Int J Adv Manuf Technol 78: $1803-1812$

62. Macedo FTB, Wiessner M, Bernardelli GC, Kuster F, Wegener K (2018) Fundamental investigation of EDM plasmas, part II: parametric analysis of electric discharges in gaseous dielectric medium. Procedia CIRP 68:336-341

Publisher's note Springer Nature remains neutral with regard to jurisdictional claims in published maps and institutional affiliations. 